\title{
Knowledge, treatment seeking and preventive practices in respect of malaria among patients with HIV attending Lagos University Teaching Hospital, Nigeria
}

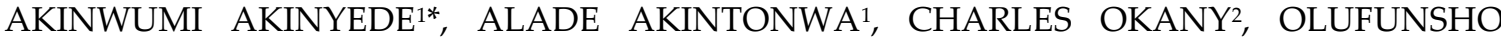

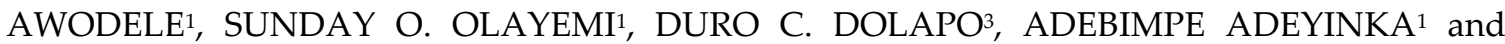 \\ ADEMOLA YUSUF1 \\ ${ }^{1}$ Department of Pharmacology, College of Medicine, University of Lagos, Lagos, Nigeria \\ ${ }^{2}$ Department of Haematology and Blood Transfusion, College of Medicine, University of Lagos, Nigeria \\ ${ }^{3}$ Department of Community Health, Lagos University Teaching Hospital, Lagos, Nigeria
}

\begin{abstract}
The synergistic interaction between Human Immunodeficiency virus (HIV) disease and Malaria makes it mandatory for patients with HIV to respond appropriately in preventing and treating malaria. Such response will help to control the two diseases. This study assessed the knowledge of 495 patients attending the HIV clinic, in Lagos University Teaching Hospital, Nigeria. Their treatment seeking, preventive practices with regards to malaria, as well as the impact of socio - demographic / socio - economic status were assessed. Out of these patients, 245 $(49.5 \%)$ used insecticide treated bed nets; this practice was not influenced by socio demographic or socio - economic factors. However, knowledge of the cause, knowledge of prevention of malaria, appropriate use of antimalarial drugs and seeking treatment from the right source increased with increasing level of education $(\mathrm{p}<0.05)$. A greater proportion of the patients, 321 (64.9\%) utilized hospitals, pharmacy outlets or health centres when they perceived an attack of malaria. Educational intervention may result in these patients seeking treatment from the right place when an attack of malaria fever is perceived.
\end{abstract}

Key words: malaria, knowledge, treatment, prevention, HIV patients, Nigeria

\section{Introduction}

Malaria accounts for more than 1 million deaths each year (WHO, 2008; Hochman \& Kim, 2009) of which about $90 \%$ occur in sub-Saharan Africa, where malaria is the leading cause of mortality in children (Murphy \& Breman, 2001; Samba, 2001). It is estimated that 300-500 million Africans suffer from malaria each year (WHO, 2006). The problem of malaria has been largely unresolved in sub-Saharan Africa due to poverty which is linked with unsanitary environmental conditions, a breeding ground for mosquitoes. Poverty also prevents access to the right choice of drugs (White et al., 1999; Phillips, 2001).

The emergence of the Human Immune Deficiency Syndrome (HIV/AIDS) in the last three decades compounded the health problems caused by malaria in sub-Saharan Africa because of its associated morbidity and mortality. AIDS is stated to be the leading cause of death among adults in Africa (Kates et al., 2002). Co-infection of an individual by malaria and HIV make the prognosis of the two diseases worse because of the various ways these ailments interact. HIV infection increases the incidence and severity of clinical malaria (WHO, 2004a). This occurs by impairment of T-cell immunity, which is of crucial importance for anti-malaria responses (Good \& Doolan, 1999). In non- 
pregnant adults, HIV infection has been found to roughly double the risk of malaria parasitaemia (Whitworth et al., 2000) and clinical malaria. In east and southern Africa, where HIV prevalence is near $30 \%$, it is estimated that about one-quarter to one-third of clinical malaria in adults can be accounted for by HIV (UNICEF, 2003). Malaria infection activates T-cells, promoting HIV replication (Xiao et al., 1998; Froebel et al., 2004) therefore accelerating HIV transmission, progression to AIDS and death (Mankowski et al., 1998; Graziosi \& Pantaleo, 1998; Kublin et al., 2005).

The associations between malaria and HIV infections imply that prevention of malaria among HIV infected patients will be beneficial to the control of HIV. Ultimately, there will also be a better control of malaria since the incidence and severity of malaria will be reduced. The use of preventive measures, such as insecticide treated nets (ITNs), indoor residual spraying of insecticides, is cardinal to the control of malaria. Recognition of the importance of measures which prevent transmission of malaria has led to the distribution of free ITNs (Cohee et al., 2009). Recipients of free ITNs include patients who attend the HIV clinics in Nigeria. Appropriate use of antimalarials as prophylaxis or curative regimen will prevent the establishment of parasites in humans, eliminate the parasites quickly and fully, therefore minimizing the possibility of resistance formation as well as malaria endemicity (White, 1997; Oreagba et al., 2008). Appropriate use of antimalarials can be achieved only if people seek medical care from the right facility during an attack of malaria fever.

A previous study among non-HIV infected individuals in Lagos, Nigeria suggests a low impact of campaigns promoting the use of ITNs (Olayemi et al., 2004). There is a dearth of information about the use of various preventive and curative measures against malaria by people living with HIV/AIDS. It is therefore important to assess the use of preventive measures against malaria and antimalarials use by these patients with the HIV infection. Therefore, this present study was carried out to ascertain the knowledge, treatment and preventive practices in respect of malaria among patients with the Human Immunodeficiency virus infection attending the Lagos University Teaching Hospital.

\section{Materials and Methods}

\section{Study site and design}

The study was carried out in the Lagos University Teaching Hospital (LUTH), Lagos, Nigeria. LUTH, located in Lagos is one of the largest teaching hospitals in Nigeria. Though most of the patients who attend LUTH are residents of Lagos, others are referred from health facilities in neighbouring states. The teaching hospital has 761 bed spaces and records over 9,000 patient's attendance every month. LUTH has a well established HIV/AIDS clinic sponsored by the Federal Government of Nigeria and the American Government, under the United States President's Emergency Plan for AIDS Relief Programme. Over 80 patients attend the HIV/AIDS clinic daily. 
This was a prospective study of the knowledge, preventive practices and treatment seeking practices in respect of malaria among patients attending the HIV/AIDS clinic in Lagos University Teaching Hospital.

\section{Sampling and sample size}

The minimum number of patients required for this study was calculated to be 65 based on the prevalence of HIV in Nigeria stated to be $4.4 \%$ (NACA, 2006). The formula: $\mathrm{N}=\mathrm{p}$ $\mathrm{q} / \mathrm{E}^{2} \mathrm{X}(1.96)^{2}$ was used for this calculation (Cochran, 1963). We recruited 495 patients which is approximately 7 times the minimum required number, thus increasing the power of the data obtained. Patients, who had been diagnosed with HIV infection by consultant physicians at the HIV clinic, were recruited into the study. The convenience sampling technique was used for this study. Thus, 741 consecutive patients were approached with explanation about the study. They were assured about their safety and observance of standard patient's confidentiality. Eventually, 495 patients who gave their consent were enrolled.

\section{Inclusion and exclusion criteria}

Patients included in this study were those confirmed to be sero-positive by the Western blot technique, permanently resident in Nigeria who agreed to be part of this study. Patients who were critically ill were excluded.

\section{Data collection}

An interviewer administered structured questionnaire was used. The questionnaire was divided into three sections. Section 1 included details of the identification number of the patient, date and demographic characteristics including age, sex, educational qualification, employment status, occupation and marital status. Section 2 contained knowledge about the cause of malaria, how malaria can be prevented, symptoms of malaria and the correct use of antimalarial drugs, while section 3 was to determine where the patients sought medical care whenever there was a perception of malaria fever and the various preventive measures used against malaria infection.

\section{Data analysis}

Simple percentages were used in the analysis and interpretation of the results. Chisquare was used to compare associations, and statistical significance was at $\mathrm{P}<0.05$.

\section{Ethical considerations}

Ethical clearance was obtained from the Ethics Committee of Lagos University Teaching Hospital and the rules guiding research when using human models was adhered to.

\section{Result}

\section{Demographic characteristics}


A total of 495 patients were enrolled in the study. The age range for the patients reviewed was between 16 - 65 years with a mean of $37.5 \pm 19.5$ years (Table 1). The male to female ratio was approximately $0.7: 1$. Out of these patients, $301(60.8 \%)$ were married while $138(27.9 \%), 30(6.0 \%)$ and $26(5.3 \%)$ were single, separated, divorced or widowed respectively. Out of the patients studied, 390 (78.8\%) were employed while $105(21.2 \%)$ were unemployed (Table 2). There were $13(3.3 \%)$ professionals among these patients while $121(31.0 \%)$ and $154(39.5 \%)$ were fully skilled and partly skilled, respectively. The remaining patients, $64(16.4 \%)$ were unskilled workers. Most of the respondents had secondary or post secondary school education $211(42.6 \%), 150(30.3 \%)$ respectively, while $90(18.2 \%)$ had primary school education and $44(8.9 \%)$ did not receive any formal education.

\section{Knowledge and practice}

Of the 495 patients sampled, $425(85.9 \%)$ knew the cause of malaria, 355 (71.7\%) knew how malaria could be prevented and $245(49.5 \%)$ were aware of the symptoms of malaria (Table 3). Only $17(3.4 \%)$ of the patients knew the correct antimalarial or the dosage for the purpose of treatment while the remaining 478 (96.6\%) did not.

Table 1: Socio-demographic variables of the respondents $(\mathrm{N}=495)$

\begin{tabular}{llll}
\hline Variable & Response & Frequency & Percent \\
\hline Age (N=495) & $16-25$ & 41 & 8.3 \\
& $26-35$ & 200 & 40.4 \\
& $36-45$ & 163 & 32.9 \\
& $46-55$ & 66 & 13.3 \\
Sex (N=495) & $56-65$ & 19 & 3.8 \\
& $>65$ & 6 & 1.2 \\
Marital status (N=495) & Male & 205 & 41.4 \\
& Female & 290 & 58.6 \\
& Single & 138 & 27.9 \\
& Married & 301 & 60.8 \\
Home setting (N=301) & Separated/Divorced & 30 & 6.0 \\
& Widowed & 26 & 5.3 \\
Number of children & Monogamous & 255 & 84.7 \\
& Polygamous & 46 & 15.3 \\
& None & 195 & 39.4 \\
& $1-4$ & 247 & 49.9 \\
& $5-8$ & 50 & 10.1 \\
\hline
\end{tabular}

The various preventive measures used by these patients against malaria were insecticide treated mosquito nets (ITNs), installation of window screening nets, indoor spraying of insecticides and prophylactic antimalarial drugs. These measures were used by 245 (49.5\%), $381(77.0 \%), 376(76.0 \%)$ and $124(25 \%)$ of the patients, respectively. Reasons given for not using ITNs were difficulty with fixing them on the beds or walls and the fact that the heat generated by these nets made them uncomfortable. Sulphadoxine- 
pyrimethamine was the commonest antimalarial drug taken for prophylactic purpose by $63(50.8 \%)$ of these patients. The other preventive drugs taken included Artesunate, chloroquine, Artemisinin-combination therapy (ACT) and proguanil in $16(12.9 \%), 9$ $(7.3 \%), 3(2.4 \%)$ and $2(1.6 \%)$ cases, respectively. However $31(25 \%)$ of the patients did not indicate the specific prophylactic antimalarial drug taken. There were $464(93.7 \%)$ patients who reported experience of malaria in the past, though there was no laboratory confirmation in most cases.

A greater proportion of the patients visited the HIV/AIDS clinic, private hospitals, general hospitals, pharmacy shops and health centres whenever they perceived they had malaria fever. Thus, the number of patients who utilized these 5 facilities out of the 495 surveyed was 321 (64.9\%).Out of the remaining patients, 48 $(9.7 \%), 15(3.0 \%), 3(0.6 \%)$ and $6(1.2 \%)$ consulted patent medicine store dealers, "Neighbourhood nurses", drug hawkers and traditional medicine dealers, respectively. Seventeen $(3.4 \%)$ of these patients practiced self - medication while $54(10.9 \%)$ were treated by a member of their household.

Table 2: Socio-economic variables of the respondents

\begin{tabular}{llll}
\hline Variable & Response & Frequency & Percent \\
\hline Education (N=495) & No formal & 44 & 8.9 \\
& Primary & 90 & 18.2 \\
& Secondary & 211 & 42.6 \\
& Post-secondary & 150 & 30.3 \\
Employment status (N=495) & Employed & 390 & 78.8 \\
Occupation (N=390) & Unemployed & 105 & 21.2 \\
& Professional & 13 & 3.3 \\
& Intermediate & 38 & 9.7 \\
& Non-manual skilled & 42 & 10.8 \\
& Manual skilled & 79 & 20.3 \\
& Partly skilled & 154 & 39.5 \\
& Unskilled & 64 & 16.4 \\
Monthly income in US\$ (N=495) & $\leq 33.3$ & 6 & 1.2 \\
& $33.3-66.7$ & 40 & 8.1 \\
& $66.7-133.3$ & 52 & 10.5 \\
& $133.3-333.3$ & 89 & 18.0 \\
& $333.3-666.7$ & 23 & 4.6 \\
& $>666.7$ & 8 & 1.6 \\
& No response & 277 & 56.0 \\
\hline
\end{tabular}

\section{Association between socio-economic variables and knowledge and practice}

The marital status of the patients and levels of education were found to be significantly associated with knowledge of cause of malaria $(P<0.05)$. The single and married patients were more knowledgeable compared to the separated or divorced. Also, those with post secondary education had the greatest knowledge followed by secondary school graduates. There was significant association between the levels of education and knowledge of malaria prevention $(P<0.05)$. Those with post - secondary education were 
most knowledgeable about preventive measures followed by those who were educated up to secondary school level. The levels of education were significantly associated with the correct knowledge of the antimalarial drugs useful for treatment and also dosage regimen $(P<0.05)$. Those with post secondary education were most knowledgeable in this regard.

There was no significant association between the use of preventive measures against malaria and socio-demographic or socio-economic variables $(P>0.05)$. However, the age groups and education levels of these patients were found to be significantly associated with the place where they sought treatment when malaria fever was perceived $(P<0.05)$. Those in the range of 36 years to 45 years consulted the right health care provider most commonly, followed by patients within the age ranges of 26-35 years and 46- 55 years. Seeking treatment from the right place was found to be most among patients with post-secondary education followed by those with secondary education.

Table 3: Distribution of respondents by their knowledge and practices as regards malaria

\begin{tabular}{|c|c|c|c|}
\hline Variable & Response & Frequency & Percent \\
\hline \multirow{4}{*}{ Knowledge $(\mathrm{N}=495)$} & Knew the cause of malaria* & 425 & 85.9 \\
\hline & Knew ways of malaria prevention* & 355 & 71.7 \\
\hline & Knew the symptoms of malaria* & 245 & 49.5 \\
\hline & Knew the correct antimalarial/dosage & 17 & 3.4 \\
\hline \multirow[t]{4}{*}{ Preventive practices $(\mathrm{N}=495)$} & Insecticide Treated Net ${ }^{*}$ & 245 & 49.5 \\
\hline & Nets on all windows* & 381 & 77.0 \\
\hline & Indoor spraying * & 376 & 76.0 \\
\hline & Prophylactic anti- malaria* & 124 & 25.0 \\
\hline \multirow{6}{*}{$\begin{array}{l}\text { Preventive } \\
(\mathrm{N}=124)\end{array}$} & Sulphadoxine-pyrimethamine & 63 & 50.8 \\
\hline & Artesunate & 16 & 12.9 \\
\hline & Chloroquine & 9 & 7.3 \\
\hline & Artemisinin combination therapy & 3 & 2.4 \\
\hline & Paludrine & 2 & 1.6 \\
\hline & No response & 31 & 25 \\
\hline \multirow[t]{12}{*}{ Source of treatment $(\mathrm{N}=495)$} & Drug hawkers & 3 & 0.6 \\
\hline & General Hospital & 57 & 11.5 \\
\hline & Health Centre & 24 & 4.9 \\
\hline & HIV/AIDS clinic & 99 & 20.0 \\
\hline & Home & 54 & 10.9 \\
\hline & Neighbourhood nurse & 15 & 3.0 \\
\hline & Patient medicine store & 48 & 9.7 \\
\hline & Pharmacy & 44 & 8.9 \\
\hline & Private hospital & 97 & 19.6 \\
\hline & Self-medication at home & 17 & 3.4 \\
\hline & Traditional medicine dealer & 6 & 1.2 \\
\hline & No response & 31 & 6.3 \\
\hline
\end{tabular}

Multiple responses given*

\section{Discussion}

In Nigeria, malaria occurs in all ecological zones, Lagos inclusive (Salako, 1997). The fact that less than half of the patients knew the symptoms of malaria is a concern. This is 
against the back drop that the current health policy allows antimalarial drugs to be sold as over the counter drugs in Nigeria and campaigns are directed at the general public, encouraging them to use antimalarial drugs in the home for treatment of malaria (FMOH, 2005a; Ajayi et al., 2008). It is important to note that for home based treatment of malaria to be successful, majority of Nigerians need to know the symptoms of malaria and make correct diagnosis. The implication of this relative lack of knowledge of malaria symptoms found in this study is that many of these patients may not know when to treat themselves for malaria and those who would otherwise have visited hospitals when they suffer an attack of malaria may do so later than expected or not at all. These situations will of course constitute a draw back to the roll back malaria initiative. It is equally worrisome that only $3.4 \%$ of these patients knew the correct antimalarial drug for treatment purposes and the right dosage. This underscores the need for improved approach in the public enlightenment programmes directed at malaria control. Previous workers also concluded that there is need for massive health campaign on the proper use of antimalarial drugs in Lagos (Agbaje, 2006; Okafor \& Odeyemi, 2009)

Educational intervention will serve the purpose of improving the knowledge and therefore practice of prevention of malaria and use of drugs for curative purposes judging by the fact that this study showed an association between the higher level of educational attainment and knowledge of malaria prevention or use of antimalarial drugs.

The use of ITNs was poor with less than half of the respondents indicating that they use free nets given through campaigns. Excuses given by the patients for not using the ITNs included difficulty in mounting the nets on their beds and the fact that they feel hot when under the net. Incidentally, none of the socio-demographic or socio-economic variables was significantly associated with the use of preventive measures against malaria, including the use of ITNs. In the absence of other reasons preventing the use of ITNs, it is necessary to find solutions to these complaints made by the patients. Such solutions may include the design of wooden stilts which can be tied or bound in some other ways to beds. These stilts can be prototypes used for demonstration so that the patients can order for copies from their carpenters. Otherwise, the stilts may be made cheap and mass produced for sale at reduced rates to the patients. The ITNs can be mounted on these stilts. The use of bed nets has often been perceived to cause heat (Nuwaha, 2001), so it is understandable if these patients do not sleep under their mosquito bed nets. Resolution of the problems associated with use of ITNs especially among these patients, through public health education is very important.

As found in our study, a recent study in Nigeria also reported that sulphadoxinepyrimethamine was one of the most common antimalarial drugs prescribed by clinicians (Meremikwu et al., 2007). What is, however, of concern is the use of SP by most of the respondents, SP is currently recommended for intermittent preventive treatment among pregnant women (FMOH, 2005b). The patients should not have used malaria prophylaxis because there was no justification for such practices medically; none of these patients was pregnant. Also, some took Artesunate or ACTs for prevention of malaria fever. The unjustified use of antimalarial prophylaxis by some of these patients 
should be stopped as this can lead to resistance formation by malaria parasites. Two groups of drugs are of particular concern, Artemisinin and its derivatives and SP because the drugs are presently used in treating resistant Plasmodium falciparum (Yeung et al., 2008; Khalid et al., 2009; WHO, 2008) and prophylaxis against malaria in pregnant women, respectively (Parise et al.,1998; WHO, 2004b; Kayentao et al., 2005; Sirima et al., 2006).

The findings of this study illustrate the diversity of places where these patients sought treatment when they perceived attacks of malaria. It is encouraging that a greater proportion of these patients sought treatment for malaria at hospitals, health centres or pharmacy stores rather than "neighbourhood nurses", traditional healers, patent medicine stores or drug hawkers. Patients with HIV will receive higher quality of medical care when they report for consultation at hospitals or health centres during episodes of malaria compared with treatment at other places. Appropriate prescription of antimalarial drugs is expected at these hospitals, health centres and pharmacy outlets. Another advantage of consultations at hospitals/ health centres is that laboratory tests can be carried out to confirm malaria or detect other causes of fever. It is pertinent to note that a previous study among non-HIV subjects in Lagos revealed that a lesser proportion visited hospitals/ clinics for treatment of malaria (Otubanjo et al., 2000). Since there was significant association between the level of education of these patients and consultations at hospitals or pharmacies stores, educational intervention may result in improved practices in these patient's responses to perceived malaria fever.

In conclusion, it is the opinion of the authors that educational intervention will improve the patients' treatment seeking practices as regards malaria. Also, the design of insecticide treated bed nets should be such that heat generation will not occur with its use while obstacles to their being mounted will be eliminated.

\section{References}

Agbaje, E.O. (2006) Knowledge and misconceptions about malaria among Nigerian school children. Nigerian Quarterly Journal of Hospital Medicine 16, 102-105.

Ajayi, I.O., Falade, C.O., Bamgboye, E.A., Oduola, A.M.J. \& Kale, O. (2008) Assessment of a treatment guideline to improve home management of malaria in children in rural South - West Nigeria. Malaria Journal 7, 24.

Cochran, W.G. (1963) Sampling Techniques, $2^{\text {nd }}$ Ed, John Wiley and sons, Inc, New York. Cohee, L., Mills, A.L., Kagaayi, J., Jacobs, I., Galiwango, R., Ludigo, J., Ssekasanvu, J. \& Reynolds, S.J. (2009) High retention and appropriate use of insecticide - treated nets distributed to HIV - affected households in Rakai, Uganda: results from interviews and home visits. Malaria Journal 6, 76.

FMOH (2005a) Malaria Control in Nigeria, 2005. Annual Report of the National Malaria Control Programme in Nigeria/ Roll back Malaria, Abuja 1, 55

FMOH (2005b) Federal Republic of Nigeria National Antimalarial Treatment Policy. Abuja: Federal Ministry of Health. 
Froebel, K., Howard, W., Schafer, J.R., Howie, F., Whitworth, J., Kaleeb, P., Brown, A.L. \& Riley, E. (2004) Activation by malaria antigens renders mononuclear cells susceptible to HIV infection and reactivates replication of endogenous HIV in cells from HIV - infected adults. Parasite Immunology 26, 213 - 217.

Good, M.F. \& Doolan, D.L. (1999) Immune effector mechanisms in malaria. Current Opinion Immunology 11, 412-419.

Graziosi, C. \& Pantaleo, G. (1998) Analysis of virologic and immunologic events in HIV infection. Pathology 66, 123-127.

Hochman, S. \& Kim, K. (2009) The impact of HIV and Malaria co-infection: What is known and suggested venues for further study. Interdisciplinary Perspectives on Infectious Diseases. Tanowitz H. B., (ed.) Hindawi Publishing Corporation, New York, 10, 1155.

Kates, J., Sorian, R., Crowley, J.S. \& Summers, T. A. (2002) Critical policy challenges in the third decade of the HIV/AIDS pandemic. American Journal of Public Health 92, 1060-1063.

Kayentao, K., Kodio, M., Newman, R.D., Maiga, H., Doumtabe, D., Ongoiba, A., Coulibaly, O., Keita, A.S., Maiga, B., Mungai, M., Parise, M.E. \& Doumbo, O. (2005) Comparison of intermittent preventive treatment with chemoprophylaxis for the prevention of malaria during pregnancy in Mali. Journal of Infectious Diseases 191, 109-116.

Khalid, A.E., Elfatih, M.M, Tarig, A., Salah, H.A., Abdalla, H.E., Mahmoud, A.M., Asma, H.E. \& Ishag, A. (2009) Feasibility and acceptability of home - based management of malaria strategy adapted to Sudan' $\mathrm{s}$ condition using Artemisinin based combination therapy and rapid diagnostic test. Malaria Journal 8, 39 Kublin, J.G., Patnaik, P., Jere, C.S., Miller, W.C., Hoffman, I. F., Chimbiya, N., Pendame, R., Taylor, T.E. \& Molyneux, M.E. (2005) Effect of Plasmodium falciparum malaria on concentration of HIV-1-RNA in the blood of adults in rural Malawi: a prospective cohort study. Lancet 365, 233-240.

Mankowski, J.L., Carter, D.L., Spelman, J.P., Nealen, M.L., Maughan, K.R., Kirstein, L. M., Didier, P.J., Adams, R.J., Murphey-Corb, M. \& Zink M.C. (1998) Pathogenesis of simian immuno-deficiency virus pneumonia, an immunopathological response to virus. American Journal of Pathology 153, 1123-1130.

Meremikwu, M., Okomo, U., Nwachukwu, C., Oyo-Ita, A., Eke-Njoku, J., Okebe, J., Oyo-Ita, E. \& Garner P. (2007) Antimalariall drug prescribing practice in private and public health facilities in South-east Nigeria: a descriptive study. Malaria Journal 6, 55.

Murphy, S.C. \& Breman, J.G. (2001) Gaps in childhood malaria burden in Africa cerebral malaria, neurological sequelae anemia respiratory distress, hypoglycaemia and complications of pregnancy. American Journal of Tropical Medicine and Hygiene 64, 57- 67.

NACA (2006) HIV/AIDS Statistics. National Action Committee on AIDS. Federal Ministry of Health, Abuja, Nigeria.

Nuwaha, F. (2001) Factors influencing the use of bed nets in Mbarara Municipality of 
Uganda. American Journal of Tropical Medicine and Hygiene 65, 877-882.

Okafor, I.P. \& Odeyemi, K.A. (2009) Home management of malaria by care givers of under-five children in an urban area of Lagos, Nigeria. Nigerian Quarterly Journal of Hospital Medicine 19, 37-41.

Oreagba, I.A., Olayemi, S.O., Omotosho, S.K., Onajole, A.T., Awodele, O. \& Akinyede A.A. (2008) The use of Artemisinin Based Combination Therapies (ACTs) in Public Secondary Health Facilities in Lagos, Nigeria. The Nigerian Postgraduate Medical Journal 15, 94-100.

Olayemi, S.O., Oreagba, I.A. \& Mabadeje, A.F.B. (2004) Knowledge and practice of the use of Insecticide-treated nets among mothers in Lagos, Nigeria: A Preliminary Survey. Nigerian Quarterly Journal of Hospital Medicine 14, 181- 184.

Otubanjo, O.A., Mafe, M.A., Idowu, E.T \& Adeneye, A.K. (2000) Knowledge, attitude and perception of malaria in Lagos State. Nigerian Quarterly Journal of Hospital Medicine 10, 73 - 77.

Parise, M.E., Ayisi, J.G., Nahlen, B.L., Schultz, L.J., Roberts, J.M., Misore, A., Muga, R., Oloo, A.j. \& Steketee, R.W. (1998) Efficacy of sulphadoxine - pyrimethamine for prevention of placental malaria in an area of Kenya with a high prevalence of malaria and human immunodeficiency virus infection. American Journal Tropical Medicine Hygiene 59, 813 - 822.

Phillips, R.S. (2001) Current status of malaria and potential for control. Clinical Microbiology Reviews 14, 208 -226.

Salako, L. (1997) Malaria the unending saga. In: Coping with Treatment Failure in Malaria. Obi C. C. (ed.). Mayer and Baker, Lagos.

Samba, E. (2001) The malaria burden and Africa. American Journal of Tropical Medicine and Hygiene 64, 1-2.

Sirima, S.B., Cotte, A.H., Konate, A., Moran, A.C., Asamoa, K., Bougouma, E.C., Diarra, A., Ouedraogo, A, Parise, M.E. \& Newman, R.D. (2006) Malaria prevention during pregnancy: Assessing the disease burden one year after implementing a program of intermittent preventive treatment in Koupela district, Burkina Faso. American Journal Tropical Medicine and Hygiene 75, 205-211.

UNICEF (2003) Malaria Technical Note No 6: Malaria and HIV/AIDS. United Nations Children Emergency Fund New York.

White, N.J. (1997) Assessment of pharmacodynamic properties of antimalarial drugs in vivo. Antimicrobial Agents Chemotherapy 41, 1413-1422.

White, N.J., Nosten, F., Looareesuwan, S., Watkins, W.M., Marsh, K., Snow, R.W., Kokwaro, G., Ouma, J., Hien, T.T., Molyneux, M.E., Taylor, T.E., Newbold, C.I., Ruebush, T.K., Danis, M., Greenwood, B.M., Anderson, R.M. \& Olliar, P. (1999)

Averting a Malaria disaster. Lancet 353, 1965-1967.

Whitworth, J., Morgan, D., Quigley, M., Smith, A., Mayanja, B., Eotu, H., Omoding, N., Okongo, M., Malamba, S. \& Ojwiya, A. (2000) Effect of HIV - 1 and increasing immuno suppression on malaria parasitaemia and clinical episodes in adults in rural Uganda : a cohort study. Lancet 356, 1051-1056. 
WHO (2004) A Strategic Framework for Malaria Prevention and control during pregnancy in the African Region. World Health Organization Regional Office for Africa, Brazzaville, AFR /MAL /04 /01

WHO (2004) Malaria and HIV Interactions and their Implications for Public Health Policy. Report of a Technical Consultation. Roll Back Malaria Department. World Health Organization, Geneva, Switzerland.

WHO (2008) Global Malaria Control and Elimination: Report of a Technical Review 1718 January, 2008, Geneva Switzerland NLM classification: WC 765

WHO (2006) Guidelines for the Treatment of Malaria. Global Malaria Programme Geneva, Switzerland, Volume 2.

Xiao, L., Owen, S.M., Rudolph, D.L., Lal, R.B. \& Lal, A.A. (1998) Plasmodium falciparum antigen-induced human immunodeficiency virus type 1 replication mediated through induction of tumour necrosis factor - alpha. Journal of Infectious Diseases 177, 437-445.

Yeung, S., Damme, W.V., Socheat, D, White, N.J. \& Mills, A. (2008) Access to artemisinin combination therapy for malaria in remote areas of Cambodia. Malaria Journal 7, 84. 